\title{
Editorial
}

\section{Análisis de Citas y autocitas}

Б드녜 ET

T탐툐

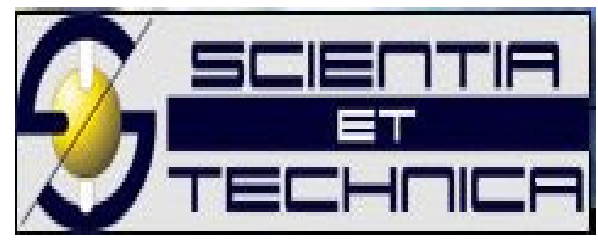

En esta entrega Editorial se comparte otro análisis deducido a partir del ejercicio de vigilancia que se inició en la edición anterior de la revista Scientia Et Technica. Estos consisten en cuantificar el número de citas que reciben las publicaciones seriadas bajo estudio.

Para este fin, se revisó la sección bibliográfica de 11015 documentos de 44 revistas nacionales que publican resultados de investigaciones en las áreas de Ingeniería y Ciencia Básica en el período comprendido entre el 2007 - 2016. Es de aclarar que a la fecha estas se encuentran indexadas y clasificadas por Colciencias.

El total de artículos revisados generó 4263 citas, las cuales corresponden a citaciones que reciben artículos de las revistas examinadas. Estas se clasificaron en Auto y No Auto citas [1]. El número total de auto citas identificadas fue de 2022 (47.2\%), el número de citas recibidas de cada Journal estudiado se enseña en el gráfico de la figura 1. Se observa que 4 de estos (Dyna, Scienthia Et Technica, Ingeniería UDEA e Investigación e Ingeniería) acaparan un buen porcentaje (55\%) de las Auto citas identificadas. 

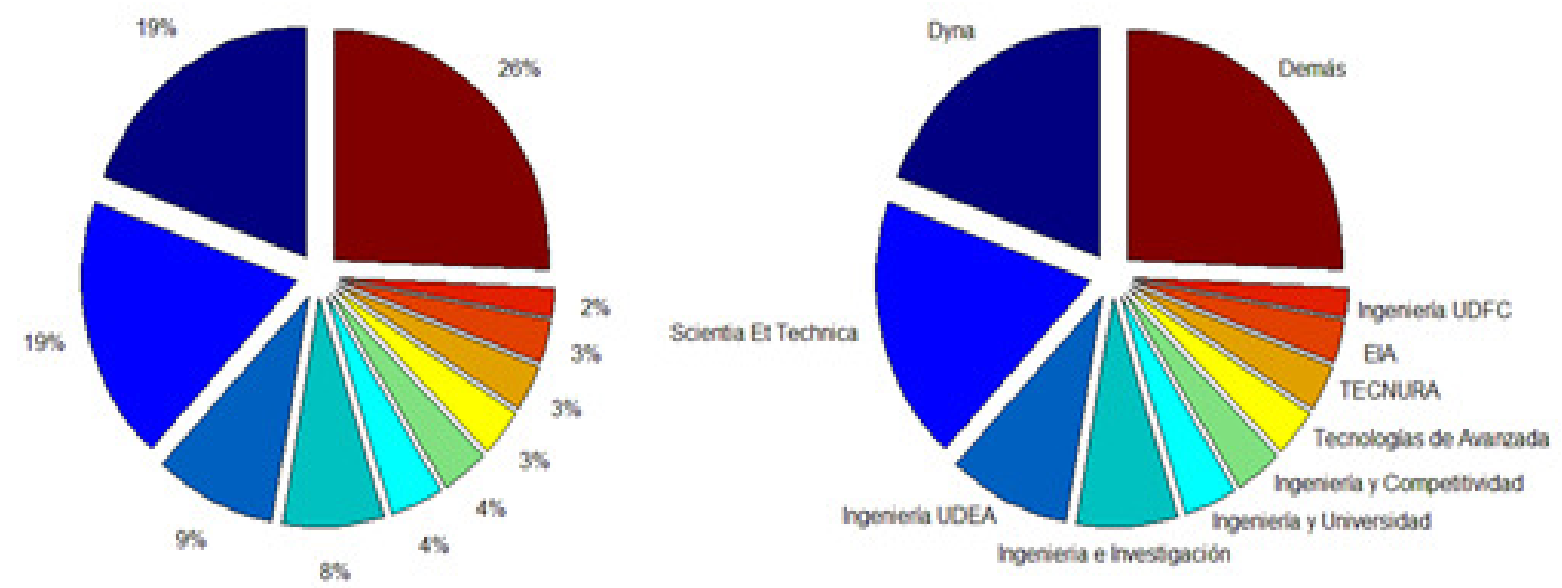

Figura 1: Porcentaje de Auto citas recibidas en cada revista.

Por otro lado, la contribución de cada revista en el número No Auto citas $(52.8 \%)$ se enseña en el diagrama de la figura 2. Similarmente la mayoría (51\%) de las citas se concentra en 3 Journal (Dyna, Scienthia Et Technica e Ingeniería e Investigación).
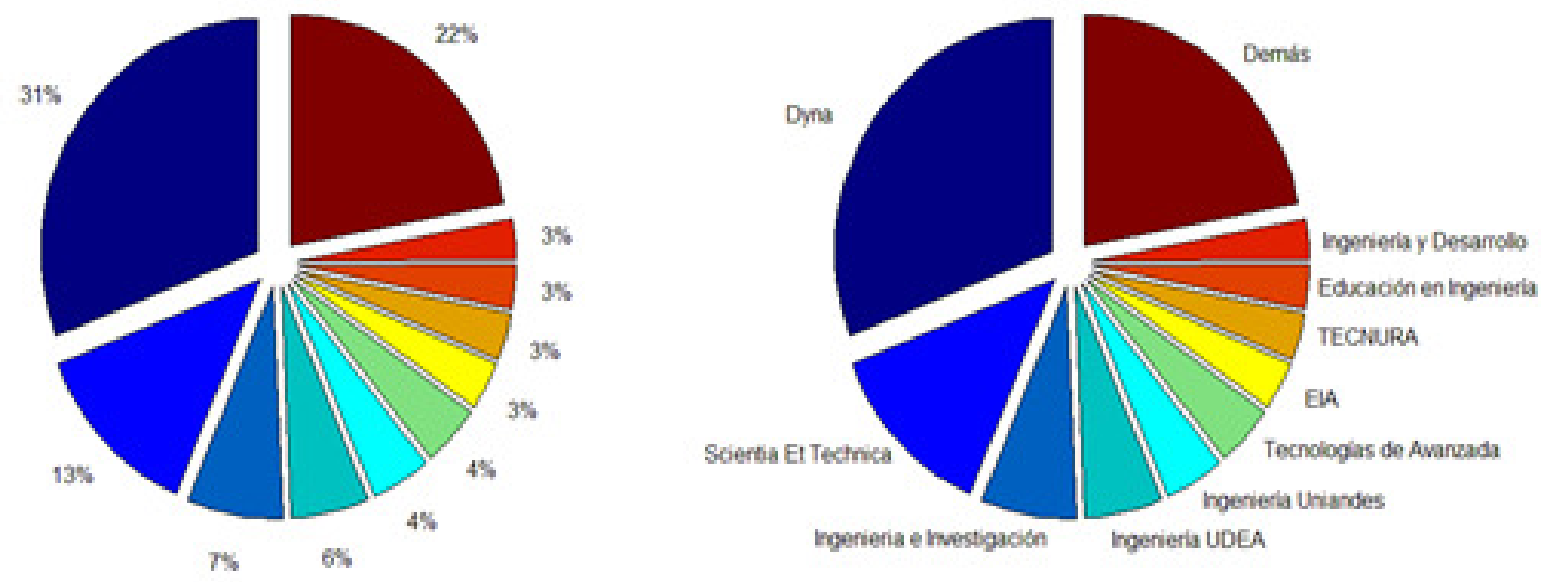

Figura 2: Porcentaje de No Auto citas recibidas en cada revista.

En el gráfico de la figura 3 se observa el acumulativo del total de citas recibidas por cada revista. Es de notar que el 55\% del total de citas identificadas se concentra en 4 Journal (Dyna, Scienthia Et Technica, Ingeniería UDEA e Ingeniería e Investigación). 

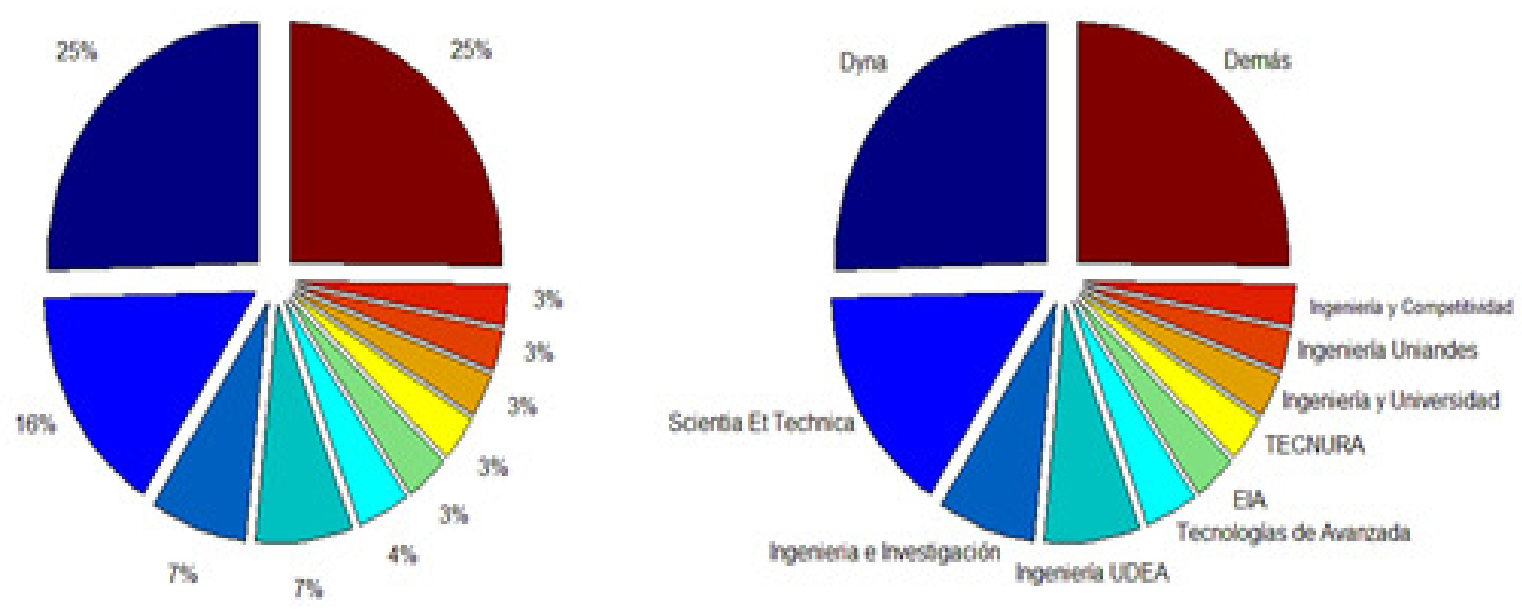

Figura 3: Porcentaje total citas recibidas en cada revista.

Es de aclarar que un porcentaje de esta cita (26.6\%) hacen referencia a artículos publicados (en las revistas bajo estudio) antes del 2007. En la figura 4 se enseña esta dinámica. Este gráfico básicamente establece que un porcentaje importantes de artículos que ya tiene una vigencia mayor a 10 años aún siguen siendo consumidos por investigadores que publican en Journal nacionales de Ingeniería y Ciencia Básica.
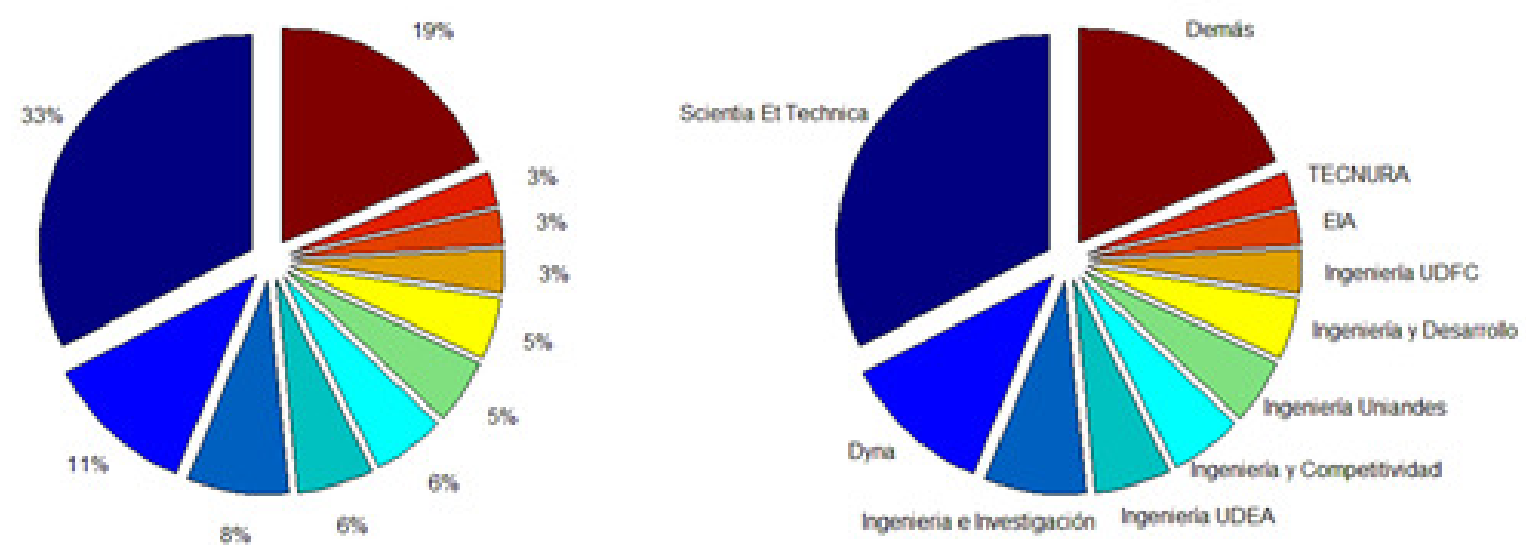

Figura 4. Citas recibidas por artículos publicados en fechas anteriores al 2007.

A continuación, se resume el origen de los artículos publicado en el gráfico de figura 5. Nótese como las revista que más publican son las que mayor número de citas reciben y por lo tanto se espera que exista una relación de causalidad entre el número de artículos publicados y el número de citas que recibe el Journal que lo publica. 

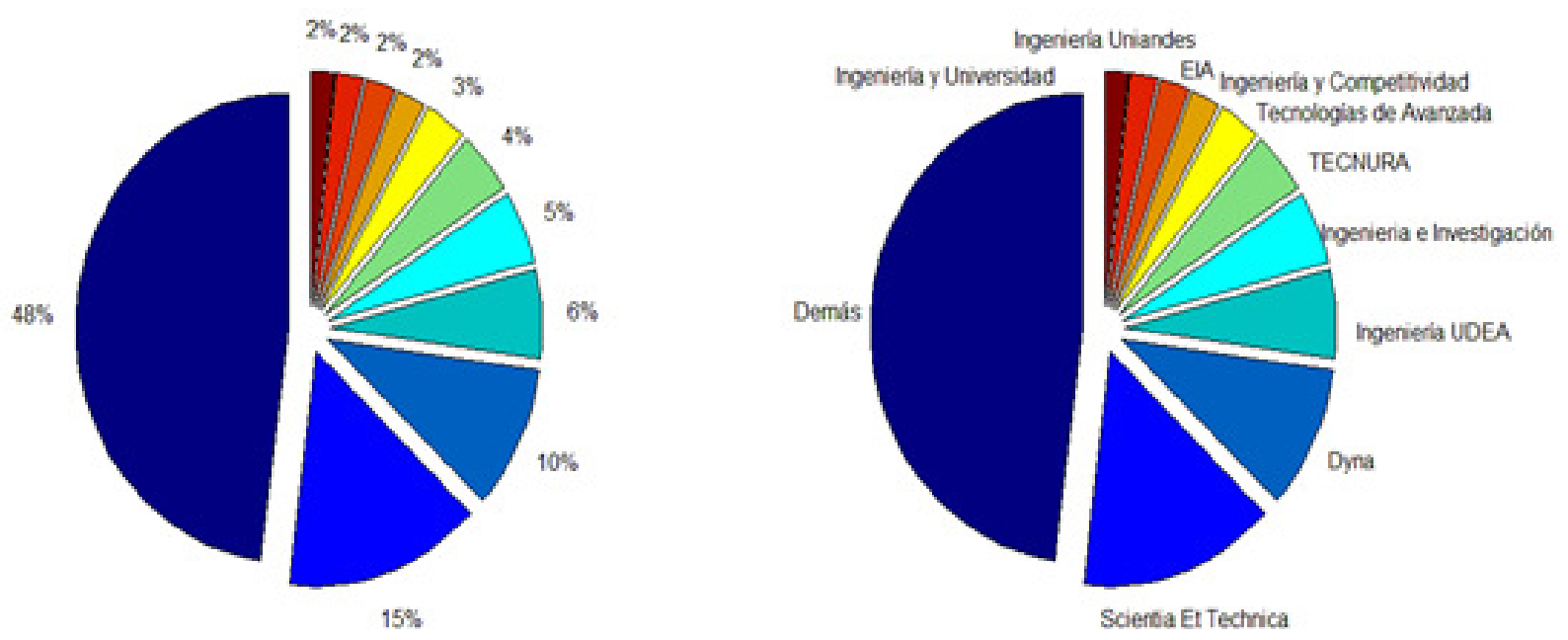

Figura 5: Porcentaje de participación académica por Revista.

Si bien los análisis no pretenden ser exhaustivos por el contrario exploratorio, es interesante como el ejercicio de vigilancia permite identificar patrones a partir de segmento vigilado. Por tanto, es importante que las revistas científicas nacionales y en el general las comunidades académicas promuevan y estimulen estos ejercicios orientados a aumentar el impacto y la aceptación de las publicaciones seriadas nacionales, a partir de una tarea constante que busca entender el entorno, observar a la competencia y así establecer rutas que permitan innovar en el proceso editorial y científico de las revistas.

\section{Referencias}

[1] INFORMACION TECNOLOGICA. Las Autocitas en Artículos de Revistas de Corriente Principal. Inf. tecnol. [online]. 2008, vol.19, n.5.

\section{Autores}

\section{Carlos Alberto Henao Baena}

Gestor Línea de Electrónica y Telecomunicaciones, Tecnoparque Nodo Pereira

\section{Andrés Felipe Calvo Salcedo}

Director Programa de Ingeniería Electrónica, Universidad Tecnológica de Pereira

\section{Hugo Armando Gallego Becerra}

Editor Scientia Et technica, Universidad Tecnológica de Pereira 